\title{
Research On The Optimum Cable Release Length Of ROVs
}

\author{
Li Lin ${ }^{1, a^{*}}$, Zhang Yanhui ${ }^{2, b}$, Yang Ping ${ }^{3, c}$ \\ ${ }^{1}$ Wuhan DongHu University, Hubei, China \\ ${ }^{2,3}$ Wuhan Rules \& Research Institute, China Classification Society, Hubei, China \\ a'6699@qq.com, bzhangyanhui@ccs.org.cn, cyangping@ccs.org.cn
}

\begin{abstract}
Keywords: self-propelled cable-controlled vehicle, cable towrope resistance, optimum cable release length.
\end{abstract}

\begin{abstract}
To study a self-propelled cable-controlled vehicle's movement, operation and control, the function of its cable's towrope resistance is needed. Through calculating towrope resistances of the vehicle under different cable release lengths, the functional relation between the vehicle's movement location and the towrope resistance, the optimum cable release length at which the towrope resistance is the smallest could be found, which provides a foundation for further research of ROVs' movement, operation and control.
\end{abstract}

\section{Introduction}

ROVs (Remotely Operated Vehicles) are usually divided into self-propelled types, drag types and sea bottom crawling types. A self-propelled, cable-controlled vehicle is the self-propelled type's ROV with a cable. It could operate in underwater areas in front of the mother ship to ensure the safety of the mother ship when disposing explosives. As a result, mine hunters of the navy are equipped with those kinds of vehicles. When mine hunters are hunting mines to clear obstacles on the shipping lanes, they have a high standard of working hours -the time span of every process, i.e., exploring and locating target, launching ROV, quickly moving to approach target, identifying and destroying target, should be as short as possible. ROV's movement process from its launch to it reaching the target is what this paper mainly researches. Considering the movement process from the vehicle's launch into water to its reaching the target location, if we choose the vehicle's optimum movement route and keep the cable's towrope resistance to a minimum, the vehicle's hours underway will be a minimum. The paper mainly studies how to release the cable's length to keep its towrope resistance to a minimum in the movement process of the vehicle.

\section{Cable's Towrope Resistance and Its Optimum Release Length}

The cable's towrope resistance is the tension it has at the junction point V (As shown in Fig. 1). How big a cable's towrope resistance is not only connected to towrope speed and water flow speed, but also has something to do with the in-water cable release length EMV and the location of cable terminal V (or the location of the vehicle in the world coordinate system E- $\xi \eta \zeta$ ). Curves 1, 2 and 3 represent cables under different release lengths, they share the same two terminals $\mathrm{V}$ and $\mathrm{E}$, but their towrope resistances are different. When the vehicle moves to a certain location $\mathrm{V}(\xi, \eta, \zeta)$, different operators may release different lengths of the cable, and the cable also has various degrees of towrope resistances. Obviously, the corresponding cable release length of the minimum towrope resistance (we call it optimum cable release length) could be found through calculations, it is this paper's objective and task to find out the optimum cable release length of the vehicle's location at any given moment during its movement process to its target location. 


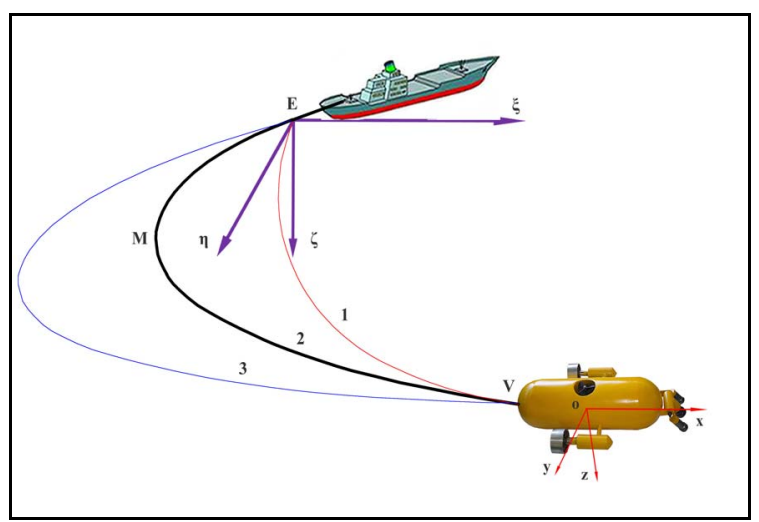

Fig. 1. A self-propelled ROV

\section{The differential equation system of the cable tension}

Since the cable is a flexible body, its tension and curve shape are described by differential equation systems $[1,2,3]$. In coordinate system E- $\xi \eta \zeta$ (see Fig. 1), the differential equation systems are as follows:

$$
\left\{\begin{array}{l}
\frac{d T}{d l}=\left(K_{r t}\right) r_{t}+\left(K_{c d}\right) p \cos \gamma \\
\frac{d \alpha}{d l}=-\frac{1}{T}\left(r_{n}-\left(K_{c d}\right) p c t g \alpha \cos \gamma\right) \\
\frac{d \beta}{d l}=\frac{1}{T}\left(r_{n} \operatorname{ctg} \alpha \operatorname{ctg} \beta-\left(K_{r t}\right) r_{b} \frac{\cos \gamma}{\sin \alpha \sin \beta}+\left(K_{c d}\right) p c \operatorname{tg} \beta \cos \gamma\right) \\
\frac{d \gamma}{d l}=\frac{1}{T}\left(r_{n} \operatorname{ctg} \alpha \operatorname{ctg} \gamma+\left(K_{r t}\right) r_{b} \frac{\cos \beta}{\sin \alpha \sin \gamma}-\left(K_{c d}\right) p \sin \gamma\right) \\
\frac{d \xi}{d l}=\cos \alpha \\
\frac{d \eta}{d l}=\cos \beta \\
\frac{d \zeta}{d l}=\cos \gamma
\end{array}\right.
$$

Here, $T(\alpha, \beta, \gamma)$ - cable's tension; $R_{t}, R_{n}, R_{b^{-}}$hydrodynamic force coefficient; $p$-the underwater gravity of cable; $K_{r t}= \pm 1, K_{c d}= \pm 1$.

To calculate the cable's towrope resistance and release length, we should solve these differential equation systems. We usually solve them through numerical computation method and could obtain the numerical solution of the cable tension as long as terminal condition and initial condition are given. Reference $[1,2,4,5]$ provides a specific method to quickly and accurately calculate cable tension.

\section{Calculation and Fitting Analysis}

To reduce the cable's horizontal acting force, the mother ship could be maneuvered to the countercurrent direction of the operation area. In world coordinate system E- $\xi \eta \zeta$ (see Fig. 1), axis E $\xi$ 's positive direction points to the target's direction in the operation area, and the horizontal distance between the operation area and the mother ship could be $\eta_{\mathrm{m}}=0$. Suppose the maximum vertical distance between them is $\xi_{\mathrm{m}}$, maximum depth is $\zeta_{\mathrm{m}}$, and the cable's towrope resistance is T, its release length is $L$, and the vehicle's movement position is $V(\xi, \eta, \zeta)$, its velocity of movement relative to the water flow is $\mathrm{v}$. The specific parameters are as follows (see Table 1):

To analyze the functional relation between the cable's towrope resistance $\mathrm{T}$ and its release length $\mathrm{L}$, we treat depth $\zeta$ and vertical distance $\xi$ as adjustable parameters, i.e., a numerical value (e.g. $5 \mathrm{~m})$ is given to depth $\zeta$ and stays unchanged, while a series of fixed value (e.g. $0 \mathrm{~m}, 50 \mathrm{~m}, 100 \mathrm{~m}, 150 \mathrm{~m}, 200 \mathrm{~m})$ 
are given to $\xi$ to do the calculation, and then another numerical value(e.g. $80 \mathrm{~m}$ ) is given to depth $\zeta$ and stays unchanged, while the same fixed value is given to $\xi$ to do the calculation, this way, a series of cable towrope resistance $\mathrm{T}$ and release length $\mathrm{L}$ could be calculated.

Table 1. The Parameters for Calculiton

\begin{tabular}{|c|c|c|c|c|}
\hline Item & \multicolumn{4}{|c|}{ Value } \\
\hline target location's coordinates & \multicolumn{4}{|c|}{$\xi_{\mathrm{m}}=200 \mathrm{~m}, \eta_{\mathrm{m}}=0 \mathrm{~m}, \zeta_{\mathrm{m}}=80 \mathrm{~m}$} \\
\hline vehicle's relative velocity of movement & \multicolumn{4}{|c|}{$\mathrm{v}=5,10 \mathrm{Kn}$} \\
\hline diameter of the cable & \multicolumn{4}{|c|}{$\mathrm{d}=6.0 \mathrm{~mm}$} \\
\hline cable's in-water weight & \multicolumn{4}{|c|}{$\mathrm{p}=0 \mathrm{~kg} / \mathrm{km}$} \\
\hline \multirow{3}{*}{ cable's hydrodynamic force coefficient } & \multicolumn{2}{|c|}{$\mathrm{C}_{\mathrm{x}}$} & \multirow{2}{*}{$\mathrm{C}_{\mathrm{y}}$} & \multirow{2}{*}{$\mathrm{C}_{\mathrm{z}}$} \\
\hline & $\alpha=0^{\circ}$ & $\alpha=90^{\circ}$ & & \\
\hline & 0.01665 & 1.10 & 0 & 0 \\
\hline
\end{tabular}

We discussed the vehicle's optimum movement routes in Reference [2], the surface channel is one of the optimum movement routes, so we select the depth $\zeta=5 \mathrm{~m}$ in the whole calculation. Table 2 displays the calculation results when $\xi=0 \mathrm{~m}(\zeta=5 \mathrm{~m})$, and results are shown in graphs as displayed in Figure 2.

Table 2. Part of Calculation Results of Cable's Towrope Resistance T and Its Release Length L

\begin{tabular}{|l|l|l|l|l|l|l|l|}
\hline $\begin{array}{c}\text { Release Length } \\
\mathrm{L}[\mathrm{m}]\end{array}$ & $\begin{array}{c}\text { Tension T } \\
{[\mathrm{N}]}\end{array}$ & $\begin{array}{c}\text { Angle } \\
\left.\alpha{ }^{\circ}\right]\end{array}$ & $\begin{array}{c}\text { Angle } \\
\left.\beta{ }^{\circ}\right]\end{array}$ & $\begin{array}{c}\text { Angle } \\
\gamma\left[^{\circ}\right]\end{array}$ & $\begin{array}{c}\text { Positon } \\
\xi[\mathrm{m}]\end{array}$ & $\begin{array}{c}\text { Position } \\
\eta[\mathrm{m}]\end{array}$ & $\begin{array}{c}\text { Position } \\
\zeta[\mathrm{m}]\end{array}$ \\
\hline 6.0 & 52.544 & 38.0735 & 90.0000 & 51.9259 & .0000 & .00 & 5.0001 \\
\hline 7.0 & 38.388 & 26.0068 & 90.0000 & 63.9940 & .0000 & .00 & 5.0000 \\
\hline 8.0 & 32.344 & 19.6765 & 90.0000 & 70.3236 & .0000 & .00 & 5.0001 \\
\hline 10.0 & 26.576 & 13.0747 & 90.0000 & 76.9253 & .0000 & .00 & 5.0001 \\
\hline 12.0 & 23.728 & 9.6867 & 90.0000 & 80.3135 & .0000 & .00 & 5.0003 \\
\hline 15.0 & 21.429 & 6.9021 & 90.0000 & 83.0979 & .0000 & .00 & 5.0001 \\
\hline 20.0 & 19.657 & 4.6148 & 90.0000 & 85.3850 & .0000 & .00 & 5.0003 \\
\hline 25.0 & 18.933 & 3.4500 & 90.0000 & 86.5499 & .0000 & .00 & 4.9999 \\
\hline 30.0 & 18.696 & 2.7546 & 90.0000 & 87.2454 & .0000 & .00 & 5.0003 \\
\hline 31.0 & 18.685 & 2.6483 & 90.0000 & 87.3517 & .0000 & .00 & 5.0003 \\
\hline 32.0 & 18.683 & 2.5498 & 90.0000 & 87.4500 & .0000 & .00 & 5.0000 \\
\hline 33.0 & 18.690 & 2.4588 & 90.0000 & 87.5410 & .0000 & .00 & 5.0000 \\
\hline 34.0 & 18.705 & 2.3745 & 90.0000 & 87.6253 & .0000 & .00 & 5.0004 \\
\hline 35.0 & 18.727 & 2.2957 & 90.0000 & 87.7042 & .0000 & .00 & 5.0003 \\
\hline 40.0 & 18.925 & 1.9720 & 90.0000 & 88.0281 & .0000 & .00 & 4.9998 \\
\hline 50.0 & 19.632 & 1.5485 & 90.0000 & 88.4512 & .0000 & .00 & 5.0001 \\
\hline 70.0 & 21.693 & 1.1061 & 90.0000 & 88.8938 & .0000 & .00 & 5.0000 \\
\hline 100.0 & 25.499 & .8025 & 90.0000 & 89.1968 & -.0002 & .00 & 5.0002 \\
\hline 200.0 & 40.114 & .4730 & 90.0000 & 89.5272 & .0004 & .00 & 5.0002 \\
\hline
\end{tabular}




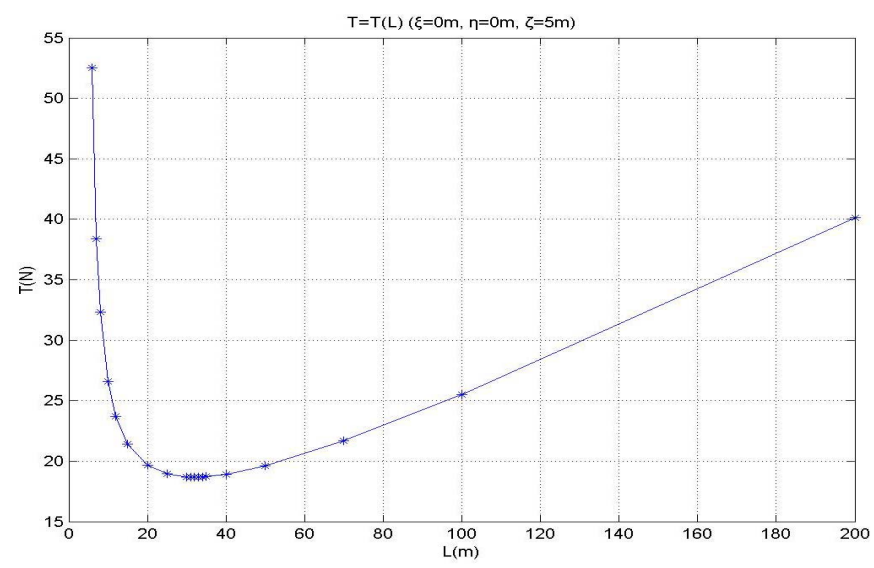

Fig. 2. The functional relation between $\mathrm{T}$ and $\mathrm{L}$

Then we calculate the cable's towrope resistance $T$ and its release length $\mathrm{L}$ when $\xi=12 \mathrm{~m}, 25 \mathrm{~m}$, $50 \mathrm{~m}, 75 \mathrm{~m}, 100 \mathrm{~m}, 150 \mathrm{~m}, 200 \mathrm{~m}$ (while $\zeta=5 \mathrm{~m}$ ), the results are similar to those of Figure 2.

The results demonstrate that optimum cable release length has an unique existence. But in the ROV's actual operation and control, we couldn't release the cable length $L$ by the functional relation $\mathrm{T}=\mathrm{T}(\mathrm{L})$, in other words, we couldn't be completely sure that the released cable length is the optimum cable length through monitoring the changing tension, so we must find the functional relation between $L$ and other variable such as position $\xi$.

We process the data (see Table 3) between optimum cable release length L and vehicle's horizontal position $\xi$, and it turns out that they have a good linear relation when $\xi>25 \mathrm{~m}$ :

Table 3. The Functional Relation Between L, T and $\xi$

\begin{tabular}{|l|l|l|l|l|l|l|l|l|}
\hline & \multicolumn{7}{|c|}{$\zeta=5(\mathrm{~m})$} \\
\hline$\xi(\mathrm{m})$ & 0.0000 & 12.1891 & 25.1812 & 50.1732 & 75.1704 & $\begin{array}{l}100.168 \\
1\end{array}$ & $\begin{array}{l}150.169 \\
0\end{array}$ & $\begin{array}{l}200.174 \\
1\end{array}$ \\
\hline L (m) & 32 & 35 & 43 & 64 & 87 & 110 & 158 & 207 \\
\hline T (N) & 18.683 & 21.055 & 24.148 & 30.940 & 38.260 & 45.822 & 61.361 & 77.197 \\
\hline
\end{tabular}

The functional relation $\mathrm{L}=\mathrm{L}(\xi)$ is shown in graphs as displayed in Figure 3, and the functional relation $\mathrm{T}=\mathrm{T}(\mathrm{L})$ is also shown in Figure 3.
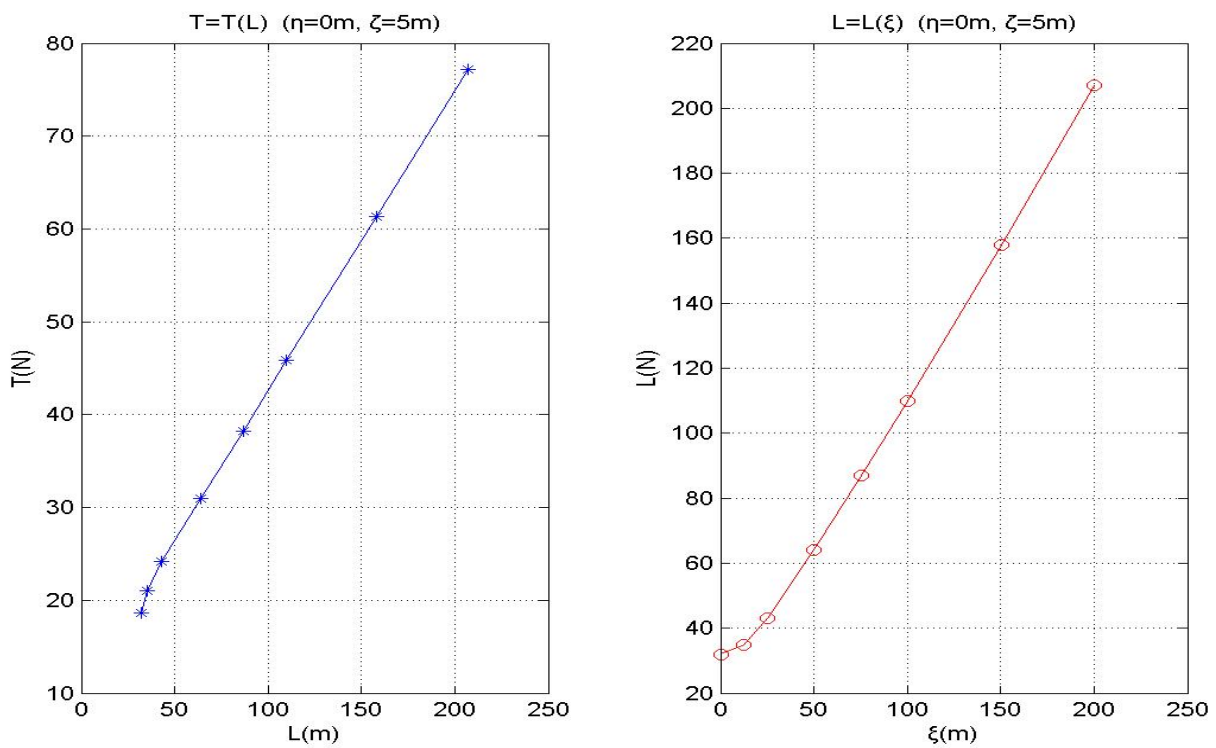

Fig. 3. Functions $\mathrm{T}=\mathrm{T}(\mathrm{L})$ and $\mathrm{L}=\mathrm{L}(\xi)$. 
Lastly we repeate the calculation when $\mathrm{v}=10 \mathrm{Kn}$, and the results are shown in Table 4 and Figure 4 . Contrasting Figure 3 and 4, we find that velocity v has little effect on the function $\mathrm{L}=\mathrm{L}(\xi)$, since ROV has different velocity, optimum cable release length stays the same. As a result, it is feasible to keep the vehicle under the optimum state of minimum cable towrope resistance by releasing the cable's length depending on ROV's movement location.

Table 4. The Functional Relation Between L, T and $\xi$

\begin{tabular}{|l|l|l|l|l|l|l|l|l|}
\hline & \multicolumn{7}{|c|}{$\zeta=5(\mathrm{~m})$} \\
\hline$\xi(\mathrm{m})$ & 0.0000 & 12.1891 & 25.1812 & 50.1732 & 75.1704 & 100.1681 & 150.1690 & 200.1741 \\
\hline $\mathrm{L}(\mathrm{m})$ & 32 & 35 & 43 & 64 & 87 & 110 & 158 & 207 \\
\hline $\mathrm{T}(\mathrm{N})$ & 74.740 & 84.227 & 96.588 & 123.776 & 153.029 & 183.300 & 245.446 & 308.804 \\
\hline
\end{tabular}
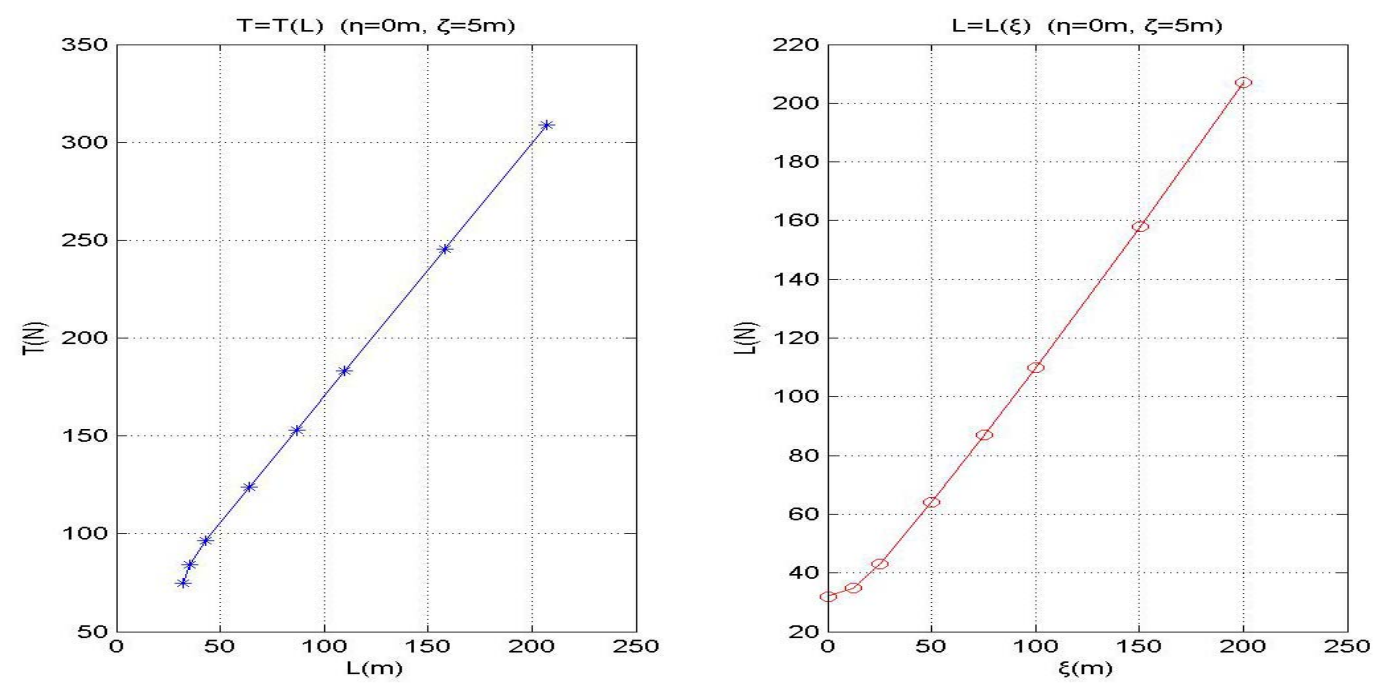

Figure 4. Functions $\mathrm{T}=\mathrm{T}(\mathrm{L})$ and $\mathrm{L}=\mathrm{L}(\xi)$

As the results of calculations and analysis have shown, with regard to a certern self-propelled cable-controlled vehicles ( $\mathrm{p}=0$, etc.), the optimum cable release length could be determined through vehicle's movement location, so that the vehicle's cable towrope resistance is kept at a minimum.

\section{Summary}

Through calculating towrope resistances of self-propelled cable-controlled vehicles under different cable release lengths, the functional relation between the vehicle's movement location and the optimum cable release length at which the towrope resistance is the smallest could be found, which provides a basis for future research of the vehicle's optimum movement route, operation and control.

\section{References}

[1] Li Lin, Zhang Yanhui, Yang Ping, The tension calculation of self-propelled, cable-controlled vehicles' cables, J. Advanced Materials Research. 823 (2013) 24-28.

[2] Zhang Yanhui, The optimization study of cable submersibles' drag resistance and motion path under extreme conditions, J. Jiangsu Ships. 22 (2005) 4-7.

[3] В.И. Егоров, Подводные буксируемые системы, Издательство Судостроение, Ленинград, 1981.

[4] Li Lin, Zhang Yanhui, Yang Ping, A method to establish motion equations of self-propelled, cable-controlled vehicles, J. Advanced Materials Research, 912-914 (2014) 545-549. 
[5] Lin Li, Deshi Wang, Dynamic behavior of remotely operated underwater vehicles with a tether, in: Yang Huayong, Li Wei, The 4th International Conference on Frontiers of Design and Manufacturing, International Academic Publishers, World Publishing Corporation, Hang Zhou, China, 2000, pp. 594-599. 